Revista Cógnito v.2:2 (2020) 240 - 262

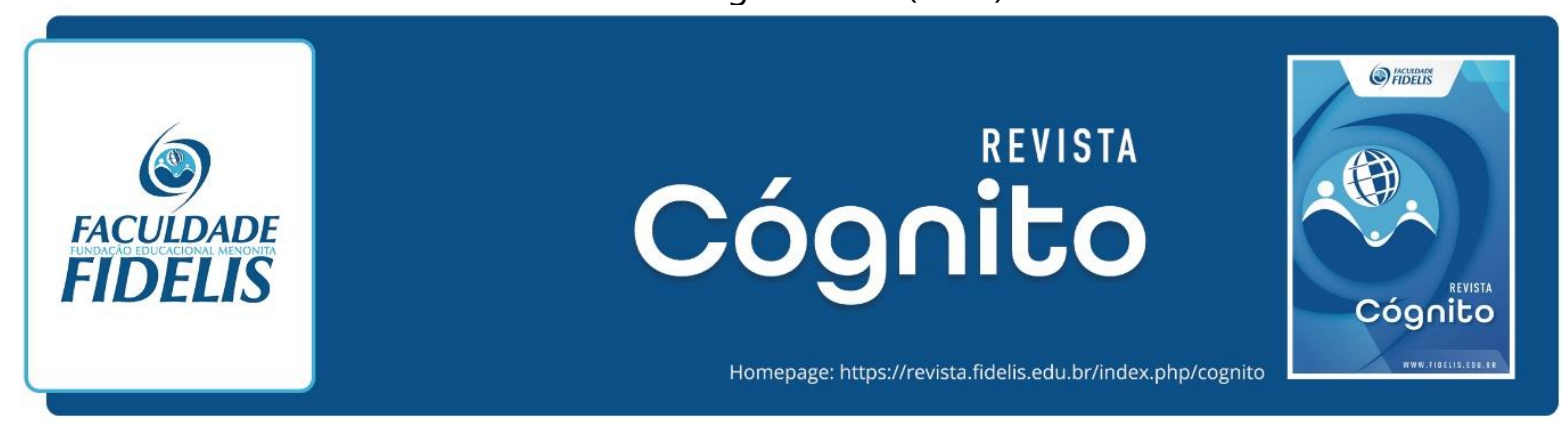

\title{
ALTAS HABILIDADES E TRANSTORNO DO DÉFICIT DE ATENÇÃO COM HIPERATIVIDADE: UMA PESQUISA BIBLIOGRÁFICA
}

\author{
HIGH ABILITIES AND ATTENTION DEFICIT HYPERACTIVITY \\ DISORDER: A BIBLIOGRAPHIC RESEARCH
}

\author{
Nayara Alves da Silva ${ }^{1}$ \\ Thiciane Pieczarka ${ }^{2}$
}

\section{RESUMO}

Esta pesquisa trata de uma pesquisa bibliográfica sobre as Altas habilidades/Superdotação e Transtorno do Déficit de Atenção com Hiperatividade. Teve como objetivo geral investigar a relação entre Altas Habilidades/Superdotação (AH/SD) e o Transtorno do Déficit de Atenção com Hiperatividade (TDAH) a partir de um levantamento bibliográfico de pesquisas empíricas. Para isto foram utilizados artigos encontrados em plataformas de buscas nacionais e internacionais, onde foram selecionados 10 artigos. A partir dos resultados foi possível concluir que existe a possibilidade de um diagnóstico equivocado, assim como a validade do diagnóstico da dupla excepcionalidade. Também foi visto sobre a necessidade de uma melhor preparação do corpo docente e da escola para o atendimento dos indivíduos com dupla excepcionalidade.

PALAVRAS-CHAVE: Altas Habilidades/Superdotação. TDAH. Educação Especial.

\begin{abstract}
This is a bibliographic research study on High Abilities/Giftedness and Attention Deficit Hyperactivity Disorder. The general objective was to investigate the relationship between High Abilities/Giftedness and Attention Deficit Hyperactivity Disorder from a bibliographic survey of empirical research. For this purpose, articles found in national and international search platforms were used, where 10 articles were selected. From the results it was possible to conclude that there is the possibility of a misdiagnosis, as well as the validity of the diagnosis

\footnotetext{
${ }^{1}$ Discente do curso de Licenciatura em Pedagogia da Faculdade Fidelis. nayara.silva@ fidelis.edu.br

${ }^{2}$ Doutora em Educação pela UFPR. Docente do curso de Licenciatura em Pedagogia da Faculdade Fidelis. thiciane.pieczarka@fidelis.edu.br
} 
of double exceptionality. It was also seen on the need for a better preparation of the teaching staff and school for the instruction of individuals with double exceptionality.

KEYWORDS: High Abilities/Giftedness; ADHD; Special Education.

\section{INTRODUÇÃO}

$\mathrm{O}$ interesse pelo tema escolhido para esta pesquisa surgiu durante o período acadêmico, após ser abordado em uma disciplina cursada ainda no segundo semestre. A partir da pesquisa realizada, foi observado que o campo das AH/SD é um campo de estudos com diversas perguntas e algumas respostas, visto que é um campo que tem sido explorado recentemente, há pouco mais de 30 anos (ANTSHEL, 2008). Assim, justifica-se o presente estudo, buscando ampliar a construção de conhecimento na educação de estudantes com $\mathrm{AH} / \mathrm{SD}$.

O campo de estudo se enquadra na Educação Especial, que segundo a Lei de Diretrizes e Bases da Educação Nacional (BRASIL, 1996) no artigo 58 é uma "modalidade de educação escolar oferecida preferencialmente na rede regular de ensino, para educandos com deficiência, transtornos globais do desenvolvimento e altas habilidades ou superdotação".

De acordo com a Política Nacional de Educação Especial na Perspectiva da Educação Inclusiva é importante ressaltar que são considerados indivíduos com altas habilidades/ superdotação:

[...] os estudantes que apontam um considerável potencial elevado em qualquer uma das seguintes áreas, isoladas ou combinadas: intelectual, acadêmica, liderança, psicomotricidade e artes. Também apresentam elevada criatividade, grande envolvimento na aprendizagem e realização de tarefas em áreas de seu interesse. (BRASIL, 2007, p. 15).

Estudos apontam que estudantes com AH/SD podem apresentar dificuldades para se relacionar com seus professores, devido ao fato de suas habilidades e interesses não serem levados em consideração no momento de atividades propostas pelos docentes (PAIVA, 2015) também podem apresentar dificuldades como qualquer outra pessoa em qualquer disciplina, mas ainda assim demonstrar ótimos resultados globais e/ou específicos (AZEVEDO; METTRAU, 2010). Esta dificuldade na relação com o docente também pode ocorrer pela falta de interesse do aluno, falta de motivação e, até mesmo, ao fato daquele indivíduo não ter sua alta habilidade em todas as áreas do conhecimento, podendo ter até dificuldades em alguma área (ALENCAR; FLEITH, 2001). 
Nesse sentido, é necessário compreender as especificidades e individualidades desses estudantes. Além disso, algumas pesquisas mostraram que existem comportamentos que podem ser semelhantes entre AH/SD e Transtorno do Déficit de Atenção com Hiperatividade (TDAH), assim como citado por Pérez e Rodrigues (2013, p.24)

É bastante comum que profissionais da área da saúde, quando não têm conhecimento sobre as $\mathrm{AH} / \mathrm{SD}$, diagnostiquem as $\mathrm{PAH} / \mathrm{SD}{ }^{3}$ como pessoas com TDAH, pela semelhança entre os sintomas do TDAH e alguns comportamentos de AH/SD.

Inclusive existem pesquisas que relatam a possibilidade de existir uma dupla excepcionalidade, segundo Budding e Chidekel (2012, p. 145) este é um "termo usado para descrever crianças superdotadas com dificuldades de aprendizagem, transtorno do espectro autista e ou transtorno do déficit de atenção com hiperatividade". Ainda a respeito disso Alves e Nakano (2015, p. 351) descrevem que:

[...] apesar de condições diferentes, apresentam inúmeras habilidades semelhantes, tais como uma fala rápida, impulsividade, alta sensibilidade à estimulação ambiental, intensa curiosidade, tendência a misturar realidade e ficção, comportamentos exacerbados, constantes queixas comportamentais por parte de seus cuidadores, e dificuldades de ajustamento a novos ambientes.

Apesar desses registros, estudos sobre a relação entre AH/SD e TDAH ainda são escassos. O que pode indicar que as características comportamentais dos estudantes podem encobrir as condições e aprendizagem. O que permite a hipótese de não identificação de estudantes com altas habilidades/superdotação, e consequentemente, a falta de acesso a um atendimento educacional especializado adequado, quando seu comportamento é mais chamativo.

A presente pesquisa tem como objetivo geral investigar a relação entre $\mathrm{AH} / \mathrm{SD}$ e o Transtorno do Déficit de Atenção com Hiperatividade (TDAH). Para tanto, propõe-se os seguintes objetivos específicos:

a) Compreender as características das $\mathrm{AH} / \mathrm{SD}$;

b) Conhecer os sintomas do TDAH;

c) Descobrir na literatura pesquisas empíricas sobre a relação entre AH/SD e TDAH;

O presente trabalho está organizado a partir de uma revisão bibliográfica, e contará com os temas AH/SD, TDAH e a aproximação desses temas. Em seguida serão apresentados os resultados coletados por meio da pesquisa bibliográfica e por fim as considerações finais.

\footnotetext{
${ }^{3}$ Pessoas com Altas Habilidades/Superdotação
} 


\section{FUNDAMENTAÇÃO TEÓRICA}

Como foco principal da pesquisa, inicialmente é necessário saber sobre as origens das $\mathrm{AH} / \mathrm{SD}$ e seu desenvolvimento até o presente momento. Além disso, é importante compreender como estes indivíduos são reconhecidos atualmente e quais leis lhes dão suporte educacionalmente. Pontos importantes sobre as características da AH/SD e informações sobre seu processo de identificação também fazem parte desta fundamentação.

Assim como o que é o transtorno de déficit de atenção com hiperatividade, suas características e qual a relação delas com as AH/SD no seu processo de identificação.

\subsection{ALTAS HABILIDADES/SUPERDOTAÇÃO: UMA CONSTRUÇÃO HISTÓRICA}

Os registros de indivíduos que se destacavam por sua inteligência e aptidões datam desde antes de Cristo (RANGNI; COSTA, 2011). Na Antiguidade a inteligência era valorizada e esses sujeitos, que se sobressaiam por conta de suas habilidades e talentos, eram encaminhados para desenvolverem suas habilidades de acordo com a cultura em que estavam inseridos (RANGNI; COSTA, 2011).

Grandes pesquisadores marcaram o início dos trabalhos sobre a inteligência humana. Na Inglaterra, Francis Galton (1869), primo de Charles Darwin, e na França, Alfred Binet (séc XIX) são os primeiros nomes vistos na história das AH/SD (RANGNI; COSTA, 2011). Binet, junto com Theodore Simon, a pedido do governo francês, criaram, em 1905, um instrumento que possibilitaria prever quais crianças teriam menos condições de acompanhar a escola regular, esse instrumento era responsável por testar as habilidades nas áreas verbal e lógica (RANGNI; COSTA, 2011). Esse instrumento baseou e auxiliou a origem do primeiro teste de QI, que foi desenvolvido por Lewis Terman nos Estados Unidos da América alguns anos mais tarde, em 1916, sendo chamado de Standford-Binet Intelligence Scale (RANGNI; COSTA, 2011; ALENCAR; FLEITH, 2001).

Com base nos estudos de Alfred Binet e Theodore Simon (FRA), Lewis Madison Terman (EUA) trouxe a primeira definição reconhecida cientificamente, em 1925, que reconhecia os scores de QI acima de 135 no teste de inteligência Standford-Binet para identificação dos superdotados (ALMEIDA; CAPELLINI, 2013).

Anos mais tarde pesquisadores como Joy Paul Guilford (EUA), nas décadas de 1960 e 1970, e Howard Gardner (EUA) e Robert Sternberg (EUA) na década de 1980 e 1990, trouxeram contribuições teóricas para o tema das AH/SD. Suas teorias passaram a defender 
uma visão de inteligência multidimensional (ALENCAR; FEITH, 2001) diferente do que era estudado até então, a unidimensionalidade da inteligência.

A teoria de Guilford, chamada de "Estrutura do Intelecto" (ALENCAR; FLEITH, 2001, p. 30) compreendia um modelo composto por três dimensões, no qual ele os intitulou de: operações; produtos; e conteúdos. Sendo que as operações tratam da forma como o indivíduo lida com as informações recebidas, o conteúdo diz respeito as classes ou tipos de informações que o organismo é capaz de diferenciar e por fim os produtos podem ser considerados como as formas que a informação toma quando é processada pelo organismo (ALENCAR; FLEITH, 2001).

Nas contribuições elaboradas por Sternberg, o autor traz a "Teoria Triárquica da Inteligência Humana" (ALENCAR; FLEITH, 2001, p. 32). Nessa teoria a inteligência é associada ao mundo interno e externo do indivíduo, assim como as experiências pelas quais o indivíduo passa (ALENCAR; FLEITH, 2001). Esse trio é composto por subcategorias interrelacionadas, sendo elas: componencial, que traz a relação da inteligência com o mundo interno; a experiencial, que consiste na habilidade de lidar com o novo e de automatizar o processamento da informação; e a contextual, que trata da relação entre a inteligência e o mundo externo (ALENCAR; FLEITH, 2001).

A teoria mais conhecida e divulgada no Brasil é a de Gardner: "a Teoria das Inteligências Múltiplas" (ALENCAR; FLEITH, 2001). Essa teoria compreende um total de sete tipos de inteligência, sendo elas: linguística, musical, lógico-matemática, espacial, cinestésica, interpessoal, intrapessoal e a naturalista (ALENCAR; FLEITH, 2001), e mais recentemente Gardner inseriu mais uma inteligência, a existencial (DIAS, 2019). Além disso, de acordo com essa teoria, ter uma habilidade mais elevada em uma dessas inteligências, não significa ter em todas, assim como é possível ter mais de uma alta habilidade (ALENCAR; FLEITH, 2001).

No Brasil, a história dos superdotados inicia em meados dos anos 30 com alguns escritores, como Leoni Kaseff, com seu livro "A educação dos supernormais" (ALENCAR; FLEITH, 2001). Quem contribui também para que este assunto fosse mais difundido e estudado foi a professora Helena Antipoff, que nasceu na Rússia, estudou na França e Suíça e, após, se mudou para o Brasil, mais especificadamente, Minas Gerais, a pedido do governo local (ALENCAR; FLEITH, 2001; DELOU, 2007; RANGNI; COSTA, 2011).

Antipoff (1892-1974), psicóloga e pedagoga, foi uma grande pesquisadora e educadora da Educação Especial, contribuindo com várias publicações acerca da necessidade de identificação precoce do superdotado e de serviços educacionais especiais para alunos que se destacavam por suas habilidades (ALENCAR; FLEITH, 2001). 
Em 1962, Helena Antipoff criou em Minas Gerais um programa para atender alunos superdotados do meio rural e da periferia urbana. Este programa teve continuidade pelo seu filho, Daniel Antipoff, até os dias de hoje (ALENCAR; FLEITH, 2001).

Infelizmente pouco se sabe sobre o atendimento dos superdotados antes da década de 70, poucos foram os autores que fizeram referência sobre a necessidade de atendimentos especializados para estes indivíduos (ALENCAR; FLEITH, 2001).

A década de 1970 foi de grande avanço na educação dos superdotados. Em termos de Legislação com a Lei 5.692 de 1971, a qual fixa diretrizes e bases para o ensino de $1^{\circ}$ e $2^{\circ}$ graus e que traz em seu texto:

Art. $9^{\circ}$ Os alunos que apresentem deficiências físicas ou mentais, os que se encontrem em atraso considerável quanto à idade regular de matrícula e os superdotados deverão receber tratamento especial, de acordo com as normas fixadas pelos competentes Conselhos de Educação.

A partir desta lei, com a inclusão dos superdotados de forma legal, foram criadas iniciativas públicas e privadas para o atendimento educacional especializado. Em 1972, iniciou o projeto POIT (Projeto Objetivo de Incentivo ao Talento) em uma instituição particular de São Paulo, com o objetivo de dar atendimento especializado a cada aluno (ALENCAR; FLEITH, 2001). Um pouco mais tarde, em 1975, iniciou, no Distrito Federal, o Núcleo de Apoio à Aprendizagem do Superdotado, composto por uma equipe de pedagogos, psicólogos e orientadores educacionais (ALENCAR; FLEITH, 2001). Este programa oferecia oportunidades para o desenvolvimento do potencial de alunos identificados, hoje ele está em todos os estados brasileiros com o nome de: Núcleo de Atividades de Altas Habilidades/Superdotação (NAAHS) atuando com alunos matriculados na rede regular de ensino que tenham indicativo de altas habilidades ou superdotação (MEC, 2008).

Segundo Delou (2007) em 1971 foi criado um projeto prioritário ( $\left.{ }^{\circ} 35 / 1971\right)$, o qual estabelecia que a educação dos superdotados era área prioritária da educação especial. Pela primeira vez foram definidos os princípios doutrinários da educação especial para alunos superdotados, partindo do conceito que crianças superdotadas e talentosas eram:

[...] as que apresentassem notável desempenho e/ou elevada potencialidade em qualquer dos seguintes aspectos, isolados ou combinados: capacidade intelectual geral; aptidão acadêmica específica; pensamento criador ou produtivo; capacidade de liderança; talento especial para artes visuais, dramáticas e musicais; capacidade psicomotora. (DELOU, 2007. p.29)

Dentre estes princípios, um deles previa a possibilidade de se ter classes especiais em escolas regulares, contudo tinha como recomendação que os estudantes superdotados 
realizassem o máximo de atividades juntamente aos demais colegas das classes regulares. Considerando que não seria sempre possível ofertar boas condições para o desenvolvimento do aluno superdotado em classes comuns (DELOU, 2007).

Logo adiante, em 1976, foi publicado um manual da educação especial para superdotados, e dentre seus princípios um deles era de que os alunos superdotados deveriam participar de classes comuns. Mas para isso os professores destas classes deveriam ter a disponibilidade de trabalhar com programas ou atividades diferenciadas, em grupos diversificados provendo orientação e materiais adequados, ofertando assim um tratamento especial para estes indivíduos (DELOU, 2007).

Em 1993, em Lavras, Minas Gerais, a professora Zenita Guenther iniciou o Centro para Desenvolvimento do Potencial e Talento (CEDET), com o objetivo de construir um ambiente que viesse complementar a educação do aluno com altas habilidades/ superdotação (ALENCAR; FLEITH, 2001; RANGNI; COSTA, 2011). Atualmente existem mais quatro centros de educação que utilizam esta metodologia, atendendo alunos de escolas públicas e particulares.

Com a renovação da Lei de Diretrizes e Bases da Educação Nacional (LDB), em 1996, algumas garantias foram alcançadas para os alunos com AH/SD. Dentre elas o atendimento especializado no âmbito da educação escolar, sendo realizado na escola comum, conforme estabelecido no artigo 59 o qual indica que os sistemas de ensino devem assegurar aos educandos com necessidades especiais "currículos, métodos, recursos educativos e organizações específicos, para atender às suas necessidades" (BRASIL, 1996, Art. 59).

Nesse sentido Delou (2007) afirma que são indicadas mudanças pedagógicas que devem oferecer programas de enriquecimento escolar e de aprofundamento de estudos para os alunos superdotados, tendo como finalidade ajustar o ensino ao nível do desenvolvimento real dos alunos. Estas propostas são de inteira competência da escola, uma vez que podem ser realizadas nas salas de aulas regulares, nas salas de atendimento educacional especializado ou salas de recursos, divididos por áreas de talento ou de interesse (DELOU, 2007).

Dentre as especificidades de ensino próprias para o atendimento dos alunos superdotados estão previstas na LDB (BRASIL, 1996) o enriquecimento e a aceleração de estudos, que podem ser combinados, conforme as condições de atendimento da escola. Para os alunos que tem a oportunidade de enriquecer os conteúdos curriculares e o seu desempenho se distanciar do nível dos demais da turma, existe então a oportunidade de aceleração dos estudos. Esta aceleração pode ser necessária para alguns indivíduos, para seu ajustamento social e escolar. 
A aceleração trata de "cumprir o programa escolar em menos tempo" (ALENCAR; FLEITH, 2001, p.127). Pode acontecer de várias formas, uma delas é entrar "adiantado" na escola ou então “pular” séries (ALENCAR; FLEITH, 2001). A ação de enriquecimento também tem várias formas de ocorrer, sendo muito próximo da aceleração em algumas delas. É possível, por meio do enriquecimento, completar os estudos em menos tempo e ainda incluir novas unidades de estudo, ou ainda pedir ao aluno que desenvolva projetos em áreas do conhecimento (ALENCAR; FLEITH, 2001). Por último, a ação da segregação consiste em separar os alunos que são mais capazes daqueles de nível mediano, para isto é utilizado algum critério como, por exemplo, nível intelectual (ALENCAR; FLEITH, 2001). Desta forma os alunos selecionados são colocados em classe especiais ou então retirados de suas salas por um período, retornando para elas após desenvolverem e concluírem atividades em algum outro local da escola (ALENCAR; FLEITH, 2001).

Todos os métodos são acompanhados de prós e contras, situações como a maturidade física, social e emocional dos alunos devem ser levadas em conta quando se trata da aceleração, assim como na questão do enriquecimento (ALENCAR; FLEITH, 2001). A segregação pode parecer um método controverso, mas também pode ser visto com bons olhos, uma vez que pode facilitar o trabalho do professor, que teria um grupo menor e mais homogêneo para trabalhar (ALENCAR; FLEITH, 2001).

Em 2001, as Diretrizes Nacionais da Educação Especial para a Educação Básica, trazem pela primeira vez a expressão AH/SD no Brasil, de acordo com Resolução n. ${ }^{\circ}$ 02/2001:

\footnotetext{
Art. $8^{\circ}$ As escolas da rede regular de ensino devem prever e prover na organização de suas classes comuns:

IX - atividades que favoreçam, ao aluno que apresente altas habilidades/superdotação, o aprofundamento e enriquecimento de aspectos curriculares, mediante desafios suplementares nas classes comuns, em sala de recursos ou em outros espaços definidos pelos sistemas de ensino, inclusive para conclusão, em menor tempo, da série ou etapa escolar, nos termos do Artigo 24, V, "c", da Lei 9.394/96. (Brasil, 2001, Art. 8. $\left.{ }^{\circ}, \mathrm{IX}\right)$
}

Ações voltadas para a inclusão dos alunos com AH/SD, sendo as principais: aceleração, enriquecimento e segregação (ALENCAR; FLEITH, 2001), demonstram que estes alunos também têm necessidades educacionais especiais e, portanto, necessitam ser identificados e atendidos de forma especializada nas escolas em que se encontram matriculados.

Para fins de conhecimento, estimativas da Organização Mundial da Saúde (OMS) 5\% a $8 \%$ da população mundial tende a fazer parte do grupo de indivíduos com $\mathrm{AH} / \mathrm{SD}$, levando em conta que estes números consideram apenas as altas habilidades cognitivas (FAVERI; HEIZLE, 2019). Quando considerado os outros aspectos da AH/SD, como por exemplo, 
liderança, criatividade, competências psicomotoras e artísticas, as estatísticas podem chegar a $30 \%$ da população (VIRGOLIM, 2014). Levando em conta que no Censo Escolar de 2018 o total de alunos matriculados na Educação Básica era de 48.455.867 e de alunos identificados de 22.161. Se tomarmos como base a porcentagem de indivíduos com AH/SD indicada pela OMS, deveríamos ter um total de 2.422.793 alunos identificados matriculados no Ensino Básico Brasileiro (FAVERI; HEIZLE, 2019). Desta forma é possível observar que faltam muitos nesse processo de identificação.

\subsection{A ATUALIDADE DAS ALTAS HABILIDADES/SUPERDOTAÇÃO}

Como definição atual de AH/SD adotada no Brasil, de acordo com a Política Nacional de Educação Especial na Perspectiva da Educação Inclusiva são considerados indivíduos com AH/SD alunos que mostram um significativo potencial elevado em uma ou mais áreas do conhecimento, sendo elas: "intelectual, acadêmica, liderança, psicomotricidade e artes" (BRASIL, 2007, p. 15). Podem também apresentar alta criatividade, um grande envolvimento na aprendizagem e realização de tarefas em áreas de seu interesse. (BRASIL, 2007).

Além destas, algumas outras características da criança superdotada, no âmbito cognitivo, podem ser: linguagem precoce, vocabulário avançado para sua idade, habilidades de leitura e escrita com pouca idade, curiosidade, ritmo acelerado de aprendizagem, pensamento abstrato e analítico, concentração, boa memória, habilidade de gerar ideias originais, grande bagagem de informação de temas diversos e preferência pelo trabalho independente (DAVIS; RIMM, 1994 apud ALENCAR; FLEITH, 2001).

A respeito da identificação do aluno com AH/SD, faz-se necessário falar sobre os métodos utilizados para tal. Na época de Terman décadas atrás, o indivíduo identificado como superdotado era o que, após a realização do teste de QI, apresentava score acima de 130 (ALENCAR; FLEITH, 2001). Contudo após a mudança de definição e, sobretudo da influência das teorias sobre a multidimensionalidade da inteligência, a identificação tornou-se mais complexa, uma vez que não se podia confiar em um único instrumento, para não correr o risco de muitos indivíduos perderem e oportunidade de serem identificados (ALENCAR; FLEITH, 2001).

Nesse sentido, uma das maiores influências na identificação de indivíduos com altas habilidades, e uma teoria muito utilizada na definição deste campo, é a "Teoria dos Três Anéis"

${ }^{4}$ DAVIS, G. A.; RIMM, S. B. Gifted education: Matching instruction with needs. Education of the gifted and talented, p. 1-24, 1994. 
de Joseph Renzuli, psicólogo educacional (ALENCAR; FLEITH, 2001; VIRGOLIM, 2014). Esta teoria é composta por um agrupamento de três traços, sendo eles: habilidade acima da média, envolvimento com a tarefa e criatividade. A representação gráfica abaixo demonstra a relação entre os três anéis.

FIGURA 1 - Representação gráfica da definição de superdotação

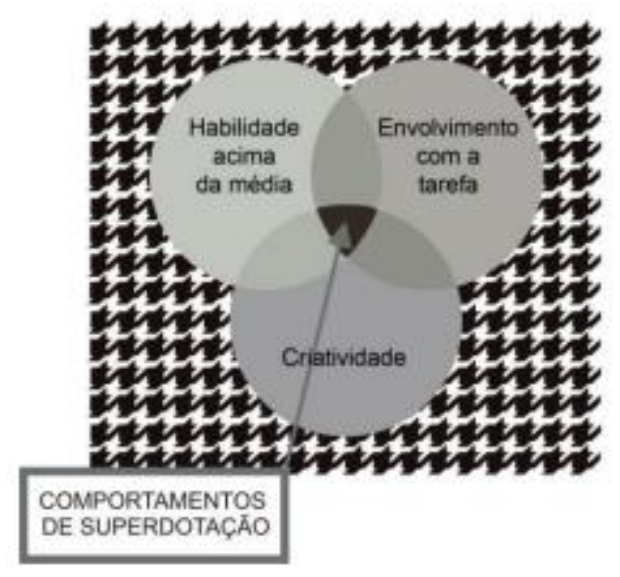

Fonte: Joseph Renzulli, traduzida e adaptada por Virgolim (2014)

Segundo as autoras Alencar e Fleith (2001, p. 58-59) estes traços são caracterizados das seguintes formas:
Habilidade acima da média envolve tanto as habilidades gerais, que consistem na capacidade de processar informações, de integrar experiências que resultam em respostas adaptativas e apropriadas a novas situações e na capacidade de se engajar em pensamento abstrato, quanto as habilidades específicas, que consistem na capacidade de adquirir conhecimento e habilidade para atuar em uma ou mais atividades de uma área especializada.
O envolvimento com a tarefa inclui uma série de traços, como perseverança, dedicação, esforço, autoconfiança e uma crença na própria habilidade de desenvolver um trabalho importante.
Com relação à criatividade, ela envolve fluência, flexibilidade e originalidade de pensamento, abertura a novas experiências, curiosidade, sensibilidade a detalhes e ausência de medo em correr riscos.

Tendo estas características e seguindo um sistema de identificação é possível reconhecer um aluno com $\mathrm{AH} / \mathrm{SD}$.

Contudo, no processo de identificação existem algumas dificuldades, uma vez que não existe um protocolo único. "Cada profissional/equipe interdisciplinar organizará o próprio conjunto de materiais que orientará suas ações" (GUIMARÃES; OUROFINO, 2007. p. 57), ou seja, fica a critério do profissional que irá fazer as avaliações com o aluno quais procedimentos ele irá seguir para chegar à identificação. Ainda Segundo Guimarães e Ourofino (2007, p. 57): 
O processo de identificação do aluno com altas habilidades/superdotação deve envolver uma avaliação abrangente e multidimensional, que englobe variados instrumentos e diversas fontes de informações (como indivíduo, professores, colegas de turma e familiares), levando-se em conta a multiplicidade de fatores ambientais e as riquíssimas interações entre eles que devem ser consideradas como parte ativa desse processo.

Mesmo que a forma como esta avaliação será feita fique a critério de cada profissional responsável, é importante que seja feita da forma mais completa possível, envolvendo a maior quantidade de fontes e informações. Quando se trata de AH/SD com características como criatividade, aptidão artística, musical e liderança, não é possível medi-las com testes de inteligência, para isto é necessário a "utilização de instrumentos e atividades alternativas, numa perspectiva mais qualitativa para acessar esta variedade de características" (GUIMARÃES; OUROFINO, 2007, p.57)

\subsection{TRANSTORNO DO DÉFICIT DE ATENÇÃO COM HIPERATIVIDADE (TDAH)}

O Transtorno de Déficit de Atenção com Hiperatividade (TDAH) é um transtorno neurobiológico ${ }^{5}$ (APA, 2014), que segundo a OMS, afeta $4 \%$ da população mundial. De acordo com a Associação Brasileira do Déficit de Atenção (ABDA) é "o transtorno mais comum em crianças e adolescentes encaminhado aos serviços especializados” (ABDA, 2020)

Algumas características do indivíduo com esse transtorno podem ser a dificuldade demonstrada em se concentrar em uma determinada tarefa (SCHWARTZMAN, 2001) também a desatenção, hiperatividade e impulsividade, que afetam o indivíduo tanto na área comportamental quanto na área cognitiva (APA, 2014). Apresentam, além disso, pouca tolerância à frustração, baixa autoestima, irritabilidade ou variação do humor e dificuldades de relacionamento com seus pares (SCHWARTZMAN, 2001). Em alguns casos, o indivíduo pode apresentar condutas agressivas e desafiadoras, sobretudo pela dificuldade que têm em aceitar normas e limites (APA, 2014).

De um modo geral o diagnóstico de TDAH, a partir dos critérios do Diagnostic and Statistical Manual of Mental Disorders (DSM-V) (APA, 2014) pode ser de três tipos, o desatento, o hiperativo-impulsivo e o tipo combinado desatento/hiperativo-impulsivo. Para diagnóstico padrão comportamental deve ser persistente e interferir na vida social e acadêmica dos indivíduos.

\footnotetext{
${ }^{5}$ Referente a neurobiologia, área dentro da Biologia que estuda os aspectos morfológicos do sistema nervoso, suas células e organização destas dentro de circuitos funcionais que processam a informação e medeiam o comportamento.
} 
Estudos apontam que há prejuízo nas Funções Executivas de indivíduos com TDAH (UEHARA; CHARCHAT-FICHMAN; LANDEIRA-FERNANDEZ, 2013). Nesse sentido, a dificuldade de inibir um comportamento e do controle motor também afetaria as outras áreas das funções executivas: a memória de trabalho, a autorregulação, a internalização da fala e a análise e síntese do comportamento (UEHARA; CHARCHAT-FICHMAN; LANDEIRAFERNANDEZ, 2013).

Pretende-se perceber se os sintomas comportamentais nas características do indivíduo com TDAH podem ser os que acabam encobrindo a possibilidade de um diagnóstico de AH/SD.

\section{PROCEDIMENTOS METODOLÓGICOS}

A partir da escolha do tema, foram definidos termos de busca como palavras-chave: altas habilidades e transtorno de déficit de atenção e hiperatividade, com suas possíveis alterações. Após busca prévia em bases de dados nacionais, Scielo, VHL - Regional Portal e LILACS, percebeu-se a necessidade de ampliar a busca para bases internacionais, utilizando a terminologia em inglês: gifted (ou giftedness) e ADHD. Utilizamos as seguintes bases: APA PsycNet, ERIC e Scopus.

Nesta busca em bases internacionais, foi necessário fazer um primeiro corte de artigos de referência (que podem ser considerados marcos na discussão do tema em específico), artigos de revisão bibliográfica e artigos de pesquisas empíricas realizadas nos últimos 5 anos. Nesse sentido realizou-se a leitura dos resumos com o objetivo de encontrar artigos que discutissem diretamente a relação entre as duas palavras-chave propostas. Estudos que não tinham esse objetivo foram excluídos. Assim, após a leitura dos resumos foram então selecionados 10 artigos, sendo 9 na língua inglesa, que então foram lidos na íntegra e fichados, sendo apresentados de ordem cronológica a seguir.

\section{RESULTADOS E DISCUSSÃO}

Como registro mais antigo que temos de estudos sobre a dupla excepcionalidade das AH/SD e o TDAH, encontramos o artigo de Baum e pesquisadores (1998), onde é possível obter informações sobre a influência da medicação (Ritalina) nessa população e sobre as características da dupla excepcionalidade. Não sendo uma pesquisa empírica, algumas informações foram colhidas com a ajuda de pais, que se propuseram a deixar seus depoimentos 
sobre as dificuldades educacionais de seus filhos com essa dupla excepcionalidade, mas a maior parte delas veio de um levantamento bibliográfico feito pelos autores (BAUM, et. al, 1998).

Os autores afirmam que o sistema escolar não reconhece o Transtorno de Déficit de Atenção como uma incapacidade e por conta disso os educadores acabam por receber pouca orientação sobre a natureza e tipos de soluções educacionais que podem auxiliar estes indivíduos (BAUM, et. al, 1998). Quanto à medicação indicada para indivíduos com TDAH, no âmbito da dupla excepcionalidade, os médicos admitem que se as instituições escolares fossem mais receptivas às necessidades de aprendizagem individuais dos alunos, estariam mais cientes do TDAH e suas várias opções de tratamento, não sendo necessário a indicação da medicação para todos (BAUM, et. al, 1998). Se tratando da dupla excepcionalidade a preocupação mais séria é que o comportamento das AH/SD possa ser sacrificado por um comportamento mais controlável em alguns alunos criativos e brilhantes que são medicados para o TDAH (BAUM, et. al, 1998).

Como explicação para a limitação na oferta de serviços completos, diagnósticos apropriados e estratégias eficazes para os indivíduos com AH/SD e TDAH, os autores discutem o fato de, infelizmente, a maioria dos pesquisadores e profissionais envolvidos na área de TDAH terem pouco contato com especialistas na área social e desenvolvimento emocional da criança superdotada (BAUM, et. al, 1998). Assim como poucos teóricos ou profissionais da educação de superdotados estão familiarizados com a literatura da medicina, psiquiatria ou educação especial (BAUM, et. al, 1998).

Segundo Baum e colaboradores (1998) é possível que o déficit de atenção esteja ligado a inteligências específicas, e esta é uma ideia que ainda não foi investigada.

Parece que quando alguns alunos hiperativos estão encorajados a aprender e se comunicar em uma área de força (geralmente uma inteligência não verbal), até mesmo tarefas chatas são realizadas sem o acompanhamento de problemas comportamentais (BAUM, et. al., 1998, p. 100).

Evidenciando a necessidade de se ter um olhar mais individualizado para os alunos (BAUM, et. al, 1998). Inclusive estudos mostraram que modificações no currículo, ritmo e estratégias de ensino tem efeitos positivos sobre o aumento da atenção dos alunos e melhoram o comportamento e desempenho autorreguladores (BAUM, et. al, 1998).

Por fim, Baum e pesquisadores (1998) concluíram que quando se oferecem altos níveis de desafios e oportunidades de resolução de problemas, especialmente em áreas de talentos e interesses dos alunos, isto resulta em um envolvimento intencional do aluno e sustenta seu interesse em atividades de aprendizagem. 
Um estudo feito por Fleith e Ourofino (2005) teve como objetivo comparar alunos

(...) superdotados, hiperativos e superdotados/hiperativos em relação à criatividade, inteligência, autoconceito, déficit de atenção e hiperatividade/impulsividade, comportamento anti-social e dificuldades de aprendizagem (FLEITH; OUROFINO, 2005, p.165).

Para esta pesquisa foram selecionados 114 alunos, "52 alunos superdotados, 43 alunos portadores de TDAH e 19 alunos superdotados/hiperativos" (FLEITH; OUROFINO, 2005, p.165) da rede de ensino público e particular do Distrito Federal, da Educação Infantil até sexto ano do Ensino Fundamental, onde em sua maioria eram meninos (80,7\%).

Para a comparação foi utilizado uma combinação de diversos testes e instrumentos como:

Matrizes Progressivas Coloridas de Raven Escala Especial (Angelini, Alves, Custódio, Duarte \& Duarte, 1999), Escala de Autopercepção para Crianças (Harter, 1985) e Teste Torrance de Pensamento Criativo - versão figurativa (Torrance, 1990). Na segunda sessão foram aplicados o Teste Torrance de Pensamento Criativo - versão verbal (Torrance, 1990) e o Inventário de Estilos de Aprendizagem (Renzulli \& Smith, 1978, 1998). (FLEITH; OUROFINO, 2005, p.168).

As autoras obtiveram resultados que sugerem ser possível coexistir o TDAH e as AH/SD no indivíduo, assim como a proximidade das características das duas condições é o que irá estabelecer a qualidade do diagnóstico e do acompanhamento para estes sujeitos (FLEITH; OUROFINO, 2005). Levando em conta o desempenho escolar, foi verificado que "os alunos SD/TDAH apresentam dificuldades escolares, mas, devido a sua alta inteligência, desenvolvem condições positivas para mediar o transtorno e garantir sucesso acadêmico" (FLEITH; OUROFINO, 2005, p.176).

Como resultado deste estudo (FLEITH; OUROFINO, 2005) foi possível observar também que existe uma predisposição do SD/TDAH em preservar suas características de altas habilidades. E a diferença entre o grupo com AH/SD e SD/TDAH acontece de maneira expressiva com relação aos "domínios competência acadêmica e conduta comportamental" (FLEITH; OUROFINO, 2005). Desta forma, o resultado em questão pode sugerir que o indivíduo com SD/TDAH mascara sua condição de déficit de atenção, mas quando o assunto é competência acadêmica ele se percebe mais negativamente, podendo influenciar o seu comportamento. As autoras destacam ainda que crianças SD/TDAH tendem a ser as mais prejudicadas pelos diagnósticos equivocados, pois, de um lado devido à alta habilidade que pode acobertar os sintomas do TDAH e, por outro, a desatenção e a impulsividade podem 
interferir nos resultados dos testes e em seu desempenho acadêmico (FLEITH; OUROFINO, 2005).

Como conclusão do estudo, as autoras (FLEITH; OUROFINO, 2005) fazem observação quanto a preparação da escola e do corpo docente para trabalhar com os indivíduos com esta dupla excepcionalidade, uma vez que é necessário que o profissional que fará o atendimento destes alunos dedique tempo para investigar quais atividades e situações de sala de aula são mais propícias a estes alunos. E a escola terá um grande desafio, que será de se organizar para atender adequadamente o aluno SD/TDAH, que exigem um nível apropriado de desafio intelectual e tem a necessidade de apoio para desenvolverem sua maturidade social e emocional (FLEITH; OUROFINO, 2005).

No estudo de Antshel e colaboradores (2007) o objetivo foi de verificar a validade do diagnóstico do transtorno de déficit de atenção/hiperatividade (TDAH) em crianças de AH/SD e configurar as características clínicas associadas com o TDAH. Os métodos utilizados em sua pesquisa foram de selecionar apenas crianças com AH/SD com QI de escala total $\geq 120$. Nele foram identificadas 92 crianças com alto QI que não tinham TDAH e 49 crianças com alto QI que atendiam critérios de diagnóstico para TDAH, todas participaram do Massachusetts General Hospital Longitudinal Family Studies para TDAH (ANTSHEL, et. al., 2007).

Como resultados da pesquisa os participantes com AH/SD com critérios para diagnóstico de TDAH e alto QI, atenderam aos critérios para o subtipo combinado, sendo este um total de 35 crianças, ou seja, a maioria (ANTSHEL, et. al., 2007). No geral, as crianças com critérios para diagnóstico de TDAH e QI alto tiveram uma maior taxa de prevalência de TDAH familiar em parentes de primeiro grau; também repetiram séries com mais frequência, onde a pesquisa demonstrou que corresponde a um quinto dos participantes da pesquisa, evidenciando que o TDAH pode prejudicar o desempenho escolar, mesmo entre crianças com altas habilidades; sua psicopatologia de comorbidade foi maior e houveram mais deficiências funcionais em vários domínios (ANTSHEL, et. al., 2007). Portanto, para efeitos de conclusão deste estudo, todos os dados sugeriram que o diagnóstico de TDAH é válido entre crianças com AH/SD (ANTSHEL, et. al., 2007).

Antshel (2008) com base em sua pesquisa já publicada anteriormente (ANTSHEL, et. al., 2007) fez uma revisão bibliográfica, de forma a identificar a validade do diagnóstico do TDAH em indivíduos com altas habilidades, visto que este ainda é um assunto questionável. Com o apoio dos dados colhidos pela sua pesquisa (ANTSHEL, et. al., 2007) mais os que foram levantados pela revisão, é aceito que o TDAH em indivíduos com AH/SD pode sim ser válido. De modo a concluir sua revisão, o autor cita ainda que o TDAH na população com AH/SD pode 
ser muito semelhante aos sintomas de TDAH nos indivíduos de inteligência média (ANTSHEL, 2008).

Uma pesquisa realizada de forma empírica por um grupo de pesquisadores do Hospital Pequeno Príncipe (CORDEIRO, et. al, 2010), localizado na cidade de Curitiba, teve como objetivo verificar se era válido o diagnóstico de TDAH em crianças com AH/SD, uma vez que este ainda é um diagnóstico discutível. Para isto foi utilizado um tratamento multidisciplinar com critérios rigorosos de diagnóstico e alguns instrumentos psicométricos válidos internacionalmente (CORDEIRO, et. al, 2010). Para participar da pesquisa, foram selecionados 275 alunos de escolas públicas, de primeiro ao quinto ano, da cidade em questão, que haviam sido enviados previamente ao Centro de Pesquisas do Hospital com dificuldades comportamentais ou de aprendizagens (CORDEIRO, et. al, 2010). Estas crianças foram então submetidas a "avaliações clínicas, psiquiátricas, psicológicas e pedagógicas para avaliação de QI e TDAH, transtornos de aprendizagem e outros transtornos emocionais ou comportamentais" (CORDEIRO, et. al, 2010). Como resultado da pesquisa, 10 crianças com AH/SD cumpriram os critérios de diagnóstico do DSM-V (APA, 2014) para tipo combinado de TDAH. Trazendo então como conclusão da pesquisa que é válido o diagnóstico de TDAH em indivíduos com AH/SD (CORDEIRO, et. al, 2010).

Vale ressaltar que este foi o primeiro e até então o único estudo feito de forma empírica no Brasil tratando sobre esta dupla excepcionalidade, com o objetivo de validar o diagnóstico dos médicos para a dupla excepcionalidade, sendo o segundo no mundo. O outro estudo feito empiricamente foi de Antshel e colaboradores (2007) já citado acima, onde foram obtidos os mesmos resultados da validade desta dupla excepcionalidade.

Budding e Chidekel (2012) realizaram um estudo neuropsicológico que observou se, devido ao TDAH, indivíduos com AH/SD teriam uma dificuldade em "saber quando agir, saber quando não agir, saber quando manter uma ação em andamento, e saber quando não manter uma ação em andamento" (BUDDING; CHIDEKEL, 2012 p.149). Para os autores (BUDDING; CHIDEKEL, 2012), apesar de terem qualidades cognitivas, os indivíduos com AH/SD e TDAH tendem a sofrer um déficit significativo nas suas funções executivas, sendo maiores quando relacionados com a população em geral. Compreendem que isso está relacionado com o amadurecimento das áreas frontais do cérebro, uma vez que em crianças com AH/SD e TDAH estas áreas tendem a amadurecer mais lentamente (BUDDING; CHIDEKEL, 2012).

Por fim, neste estudo os autores concluem que indivíduos com TDAH e indivíduos com AH/SD podem ter as mesmas falhas nas áreas de intenção e refinamento do cérebro e suas dificuldades podem ser impulsionadas pelos mesmos esquemas biológicos (BUDDING; 
CHIDEKEL, 2012). Não deixam claro se poderia se tratar de uma dupla excepcionalidade ou de diagnósticos próximos (BUDDING; CHIDEKEL, 2012).

Em uma pesquisa Fugate, Zentall e Gentry (2013) tinham como objetivo verificar se alunos com AH/SD e características de TDAH tinham uma maior criatividade do que alunos superdotados sem as características do TDAH. Para isto foram convidados alunos superdotados que participaram de acampamentos de verão para crianças com AH/SD. Compuseram a amostra 68 alunos de quinto a décimo segundo ano escolar, de 10 a 17 anos, que cumpriram requisitos para participar da pesquisa, além de assinarem um termo de consentimento (FUGATE; ZENTALL; GENTRY, 2013). Estes 68 alunos com AH/SD foram divididos em dois grupos para o estudo, onde, um grupo era composto por 17 indivíduos que foram identificados com características de TDAH e o outro grupo com 20 alunos identificados sem estas características, concluindo a amostra. Sendo excluídos os outros 31 alunos.

Após terem sido feitos testes para medir a criatividade e memória de trabalho dos indivíduos, foi verificado uma diferença significativa entre os dois grupos estudados, indicando que o grupo dos alunos com AH/SD com características de TDAH não só tinham uma pior memória de trabalho, mas também uma criatividade consideravelmente maior do que o grupo de alunos com AH/SD sem essas características (FUGATE; ZENTALL; GENTRY, 2013).

Como implicação educacional, esta pesquisa indica que avaliações de criatividade, sendo utilizadas como um meio alternativo, podem identificar mais facilmente a dupla excepcionalidade dos estudantes com AH/SD (FUGATE; ZENTALL; GENTRY, 2013).

Lee e Olenchak (2014) também fizeram uma revisão de literatura sobre a dupla excepcionalidade de indivíduos com AH/SD e TDAH, deixando claro que esta é uma área de pesquisa garantida, uma vez que os sintomas podem se mostrar semelhantes, mas que apesar desta semelhança suas condições e causas são diferentes. E como conclusão para esta revisão foi visto que os indivíduos com diagnóstico de AH/SD e TDAH correm o risco de ter um diagnóstico incorreto, devido ao fato de termos poucas pesquisas com dados empíricos (LEE; OLENCHAK, 2014). Esta escassez dificulta também a criação de intervenções voltadas para estes indivíduos (LEE; OLENCHAK, 2014).

Em uma revisão de literatura Rommelse e colaboradores (2016) tinham como objetivo validar o diagnóstico de TDAH em indivíduos com AH/SD, visto que as AH/SD podem “imitar" os sintomas do TDAH (ROMMELSE, et. al, 2016). E mesmo que tenham sido poucos os estudos feitos até então, os resultados da revisão "sugerem que o TDAH é um construto válido no contexto das AH/SD" (ROMMELSE, et. al, 2016, p. 21), deixando evidente 
características clínicas do TDAH, com exceção da hiperatividade, sendo este um marcador patológico menos visível entre estes indivíduos.

McCoach e pesquisadores (2020) fizeram uma recente pesquisa para examinar se os alunos que foram identificados como superdotados de baixo rendimento eram mais propensos a manifestar sintomas de TDAH. A pesquisa foi composta por 212 alunos provenientes de 85 escolas diferentes, assim como 140 professores destas escolas e os pais dos respectivos alunos (MCCOACH, et. al, 2020). Estes alunos variavam entre 9 e 17 anos de idade, sendo a média de 12 anos (MCCOACH, et. al, 2020). Pouco mais de 75\% dos alunos eram do sexo masculino. Todos estes alunos eram de AH/SD e tinham um baixo rendimento (MCCOACH, et. al, 2020). A pesquisa contava com 5 questões a serem respondidas pelos pais e professores $(\mathrm{MCCOACH}$, et. al, 2020).

Como resultado desta pesquisa pais e professores avaliaram de forma considerável os alunos como apresentando maior desatenção do que a hiperatividade. Mas os professores relataram ainda mais desatenção do que os pais. Quando as escalas dos pais e dos professores foram consideradas juntas, em torno de $18,75 \%$ dos AH/SD com baixo rendimento exibiram níveis clínicos significativos de dificuldade de atenção em casa e na escola (MCCOACH, et. al, 2020).

De forma resumida, os alunos com AH/SD com baixo rendimento tiveram elevado score de desatenção e obtiveram pontuações mais baixas em todas as três subescalas SAAS-R: autoeficácia, avaliação de metas e autorregulação. Os estudantes com AH/SD com baixo rendimento exibiram taxas mais altas de desatenção em ambientes domésticos e escolares do que se esperaria de uma população escolar típica, contudo, estes indivíduos não exibiram níveis maiores de comportamentos hiperativos. Levando os autores a descobrir que uma porcentagem muito baixa de AH/SD com baixo rendimento em sua amostra tinham hiperatividade elevada. O que os levou a concluir que talvez alunos que exibem hiperatividade e impulsividade possam ser menos propensos a serem identificados como AH/SD. Sendo possível que alguns indivíduos com $\mathrm{AH} / \mathrm{SD}$ com baixo rendimento o nunca sejam identificados como talentosos $\mathrm{MCCOACH}$, et. al, 2020).

\section{CONSIDERAÇÕES FINAIS}

Os autores Fleith e Ourofino (2005), Budding e Chidekel (2012) e Rommmelse mais colaboradores (2016) reconhecem a possibilidade de um diagnóstico equivocado, uma vez que os sintomas do TDAH podem se confundir com as características das AH/SD e vice-versa. 
Ainda Budding e Chidekel (2012) ressaltam que estas duas condições podem ter a mesma falha com relação ao refinamento do cérebro (BUDDING; CHIDEKEL, 2012).

Verificou-se também nas pesquisas de alguns autores (BAUM et. al., 1998; BUDDING; CHIDEKEL, 2012; FUGATE; ZENTALL; GENTRY, 2013; LEE; OLENCHACK, 2014; MCCOACH et. al, 2020) que eles não deixam claro sobre a possibilidade do diagnóstico da dupla excepcionalidade. Contudo Baum e colaboradores (1998) levam em consideração a questão medicamentosa para a população com TDAH, onde sugerem que esta situação pode afetar na identificação das altas habilidades. Enquanto McCoach e outros autores (2020) discorrem sobre a possibilidade de indivíduos com AH/SD de nunca serem identificados, quando seu baixo desempenho escolar pode ocorrer por conta do TDAH.

Quanto à validade do diagnóstico da dupla excepcionalidade os autores Fleith e Ourofino (2005), Antshel e colaboradores (2007), Antshel (2008), Cordeiro e outros autores (2010) e Rommelse e pesquisadores (2016) acreditam que é um diagnóstico válido. Antshel e colaboradores (2007) e Cordeiro e outros autores (2010) validaram esse diagnóstico através de seus estudos empíricos. Ainda Antshel e colaboradores (2007) ressaltam que o TDAH pode prejudicar o indivíduo academicamente, mesmo tendo altas habilidades.

Por fim para os autores Fleith e Ourofino (2005) e Baum e pesquisadores (1998) existe a necessidade de uma melhor preparação e orientação ao corpo docente e da escola para o atendimento deste público com dupla excepcionalidade.

Sendo assim, este artigo foi uma breve revisão a respeito do tema de AH/SD e sua aproximação com o TDAH, observando que para a maior parte dos autores citados o diagnóstico da dupla excepcionalidade é válido. Nesse sentido afirma-se o que foi observado por Pérez e Rodrigues (2013, p. 26) que "é extremamente importante a avaliação por um profissional capacitado para fazer a identificação das AH/SD e o diagnóstico do TDAH ou por uma equipe multidisciplinar que inclua ambos os profissionais".

Portanto, é importante a melhor compreensão das características de ambos os diagnósticos, e isso implica em um preparo melhor dos profissionais de ambas as áreas na identificação dos possíveis critérios diagnósticos. Isso levará uma identificação mais acertada que pode permitir o acesso ao atendimento educacional especializado. Reitera-se o observado acerca da necessidade de oferta de programas educacionais que sejam específicos e que observem as singularidades desses indivíduos com dupla excepcionalidade (BAUM, et al, 1998; FLEITH; OUROFINO, 2005; ANSHTEL, 2008; FUGATE; ZENTALL; GENTRY, 2013). 
Assim, percebe-se ainda mais a necessidade de estudos que envolvam a dupla excepcionalidade e que possibilitem a discussão de melhores programas educacionais que auxiliem o desenvolvimento e a aprendizagem desses estudantes provendo um espaço para manifestação de suas potencialidades.

\section{REFERÊNCIAS}

ALENCAR, E. M. L. S; FLEITH, D. S. Superdotados: determinantes, educação e ajustamento. $2^{\text {a }}$ Ed. São Paulo: EPU, 2001.

ALENCAR, Eunice M. L. Soriano de. O aluno com altas habilidades no contexto da educação inclusiva. Movimento Revista de Educação do programa de pós graduação faculdade de educação. Niteroi, RJ, v. 7. P.60-69. Ano 2003. Disponível em:

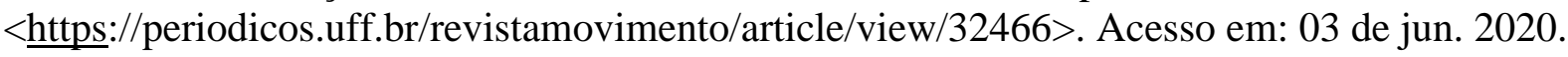

ALMEIDA, Maria Amélia; CAPELLINI, Vera Lúcia M.F. Alunos Talentosos: Possíveis superdotados não notados. In: DIETER STOBÄUS, Claus; MOURIÑO MOSQUERA, Juan José (org). Educação e inclusão: Perspectivas desafiadoras. EDIPUCRS, 2017. Disponível em: <https://books.google.com.br/books?id=ZHJqDgAAQBAJ\&hl=ptBR\&source=gbs_navlinks_s $>$. Acesso em: 11 de maio 2020.

ALVES, Rauni Jandé Roama; NAKANO, Tatiana de Cássia. A dupla-excepcionalidade: relações entre altas habilidades/superdotação com a síndrome de Asperger, transtorno de déficit de atenção e hiperatividade e transtornos de aprendizagem. Revista Psicopedagia. vol.32. $\mathrm{n}^{\circ}$.99. p.346-360. São Paulo. 2015. Disponível em: $<$ http://pepsic.bvsalud.org/scielo.php?script=sci_arttext\&pid=S0103-84862015000300008>. Acesso em: 09 de jun. 2020

AMERICAN PSYCHIATRIC ASSOCIATION (APA). Manual Diagnóstico e Estatístico de Transtornos Mentais. 5. ed. Porto Alegre: Artmed, 2014.

ANTSHEL, Kevin M. et al. Is attention deficit hyperactivity disorder a valid diagnosis in the presence of high IQ? Results from the MGH Longitudinal Family Studies of ADHD. Journal of Child Psychology and Psychiatry, v. 48, n. 7, p. 687-694, 2007. Disponível em: <https://doi.org/10.1111/j.1469-7610.2007.01735.x>. Acesso em: 28 de ago. 2020.

ANTSHEL, Kevin M. Attention-Deficit Hyperactivity Disorder in the context of a high intellectual quotient/giftedness. Developmental Disabilities Research Reviews, v. 14, n. 4, p. 293-299, 2008. Disponível em: <https://doi.org/10.1002/ddrr.34>. Acesso em: 28 de ago. 2020.

ASSOCIAÇÃO BRASILEIDA DO DÉFICIT DE ATENÇÃO (ABDA), O que é TDAH? 2020. Disponível em: <https://tdah.org.br/sobre-tdah/o-que-e-tdah/>. Acesso em: 25 de out. 2020.

AZEVEDO, Sonia Maria Lourenço de; METTRAU, Marsyl Bulkool . Altas habilidades/ superdotação: mitos e dilemas docentes na indicação para o atendimento. Psicologia: Ciência e Profissão. vol.30 n ${ }^{\circ}$, p.32-45. Brasília, 2010. Disponível em: $<$ https://www.scielo.br/scielo.php?script=sci_arttext\&pid=S141498932010000100004\&lng=en\&nrm=iso>. Acesso em: 04 de ago. 2020.

BAUM, Susan M.; OLENCHAK, F. Richard; OWEN, Steven V. Gifted students with attention deficits: Fact and/or fiction? Or, can we see the forest for the trees?. Gifted 
Child Quarterly, v. 42, n. 2, p. 96-104, 1998. Disponível em:

<https://doi.org/10.1177/001698629804200204>. Acesso em: 28 de ago. 2020.

BRASIL. Lei n ${ }^{\circ} 5.692$, de 11 de agosto de 1971. Fixa diretrizes e bases para o ensino de $\mathbf{1}^{\circ}$ e $2^{\circ}$ graus, e dá outras providências. Diário Oficial da União, 1971. Disponível em: <https://www2.camara.leg.br/legin/fed/lei/1970-1979/lei-5692-11-agosto-1971-357752publicacaooriginal-1-pl.html>. Acesso em: 14 de maio 2020.

BRASIL, L. D. B. Lei 9394/96-Lei de Diretrizes e Bases da Educação Nacional.

Disponível em: <http://www.planalto.gov.br/ccivil_03/leis/19394.htm>. Acesso em: 24 de abr. 2020

BRASIL. Resolução n. ${ }^{\circ}$ 02/2001, instrui as Diretrizes Nacionais da Educação Especial para a Educação Básica. Brasília: Conselho Nacional de Educação/Câmara de Educação Básica. 2001. Disponível em: <http://portal.mec.gov.br/cne/arquivos/pdf/CEB0201.pdf>. Acesso em: 09 de jun. 2020

BRASIL. Ministério da Educação. Secretaria de Educação Continuada, Alfabetização, Diversidade e Inclusão. Política Nacional de Educação Especial na Perspectiva da Educação Inclusiva. Brasília, DF: MEC, 2008.

BUDDING, Deborah; CHIDEKEL, Dana. ADHD and giftedness: a neurocognitive consideration of twice exceptionality. Applied Neuropsychology: Child, v. 1, n. 2, p. 145151, 2012. Disponível em: <http://dx.doi.org/10.1080/21622965.2012.699423>. Acesso em: 28 de ago. 2020.

CORDEIRO, Mara L. et al. Co-occurrence of ADHD and high IQ: a case series empirical study. Journal of attention disorders, v. 15, n. 6, p. 485-490, 2011. Disponível em: <https://doi.org/10.1177/1087054710370569>. Acesso em: 28 de ago. 2020.

DIAS, Elaine. HOWARD GARDNER: O QUE É INTELIGÊNCIA. ISI INFINITY, 2019. Disponível em: <https://isiinfinity.com.br/howard-gardner-o-que-e-inteligencia/>. Acesso em: 25 de out. 2020.

DELOU, Cristina M. C. Políticas públicas para a educação de superdotados no Brasil. In: DELOU, C. M. C.; FLEITH, D. S. ; ALENCAR, E. M. L. S. ; FRANCA, I. B. . Políticas Públicas para Identificação e Educação de Superdotados: Como Educar Talentos. 57 Reunião Anual da SBPC: Do sertão olhando o mar cultura e ciência, 2005, Fortaleza. Disponível em: <http://www.sbpcnet.org.br/livro/57ra/programas/CONF_SIMP/textos/cristinadelou.htm\#_ftn 1>. Acesso em: 09 de jun. 2020.

DELOU, Cristina Maria Carvalho. Educação do Aluno com Altas Habilidades/ Superdotação: Legislação e Políticas Educacionais para a Inclusão. In: FLEITH, Denise de Souza (org.). A Construção de Práticas Educacionais para Alunos com Altas Habilidades / Superdotação. Brasília: Ministério da Educação, Secretaria de Educação Especial, v. 1, p. 2, 2007. p. 25-40. Disponível em:

<http://www.dominiopublico.gov.br/download/texto/me004654.pdf>. Acesso em: 24 de abr. 2020.

DISRUPTIVO. In: DICIO, Dicionário Online de Português. Porto: 7 Graus, 2020.

Disponível em: <https://www.dicio.com.br/disruptivo/>. Acesso em: 20 de out. 2020.

FAVERI, Fanny Bianca Mette de; HEINZLE, Marcia Regina Selpa. Altas

Habilidades/Superdotação: políticas visíveis na educação dos invisíveis. Revista Educação Especial, v. 32, p. 118-1-23, 2019. 
FUGATE, C. Matthew; ZENTALL, Sydney S.; GENTRY, Marcia. Creativity and working memory in gifted students with and without characteristics of attention deficit hyperactive disorder: Lifting the mask. Gifted Child Quarterly, v. 57, n. 4, p. 234-246, 2013. Disponível em: <https://doi.org/10.1177/0016986213500069 . Acesso em: 28 de ago. 2020.

GUIMARÃES, Ana. Superdotação, um mito a ser quebrado. Portal MEC, 2008. Disponível em: <http://portal.mec.gov.br/ultimas-noticias/222-537011943/11472-sp1382258960>. Acesso em: 14 de maio 2020.

LEE, Kelly M.; OLENCHAK, F. Richard. Individuals with a gifted/attention deficit/ hyperactivity disorder diagnosis: Identification, performance, outcomes, and interventions. Gifted Education International, v. 31, n. 3, p. 185-199, 2015. Disponível em: <https://doi.org/10.1177/0261429414530712>. Acesso em: 28 de ago. 2020.

MCCOACH, D. Betsy; SIEGLE, Del; RUBENSTEIN, Lisa DaVia. Pay attention to inattention: Exploring ADHD symptoms in a sample of underachieving gifted students. Gifted Child Quarterly, v. 64, n. 2, p. 100-116, 2020. Disponível em: <https://doi.org/10.1177\%2F0016986219901320>. Acesso em: 28 de ago. 2020.

Neurobiológico. In: Dicionário in Formal, 2020. Disponível em: <https://www. dicionarioinformal.com.br/neurobiol\%C3\%B3gico/>. Acesso em: $11 \mathrm{de} \mathrm{dez.} 2020$.

OUROFINO, Vanessa T.A.T. de; FLEITH, Denise de Souza. Um estudo comparativo sobre a dupla excepcionalidade superdotação/hiperatividade. Avaliação Psicológica, v. 4, n. 2, p. 165-182, 2005. Disponível em: 〈https://www.redalyc.org/articulo.oa?id=335027498008>. Acesso em: 28 de ago. 2020.

PAIVA, Maria Lúcia da Silva. Dificuldades no trabalho com alunos com Altas habilidades/Superdotação segundo docentes do Ensino Fundamental. Monografia (Especialização em Desenvolvimento Humano, Educação e Inclusão Escolar)-Universidade de Brasília, Universidade Aberta do Brasil, Brasília. 2015. Disponível em: <https://bdm.unb.br/handle/10483/15894>. Acesso em: 04 de ago. 2020.

PÉREZ, Susana Graciela Pérez Barrera; FREITAS, Soraia Napoleão. Políticas públicas para as Altas Habilidades/Superdotação: incluir ainda é preciso. Revista Educação Especial, v. 27, n. 50, p. 627-640, 2014. Disponível em:

<https://periodicos.ufsm.br/index.php/educacaoespecial/article/view/14274>. Acesso em: 12 de maio 2020.

PÉREZ, Susana Graciela Pérez Barrera. RODRIGUES, Sheila Torma. Pessoas com Altas Habilidades/Superdotação: das confusões e outros entreveros. Revista Brasileira de Altas Habilidades/Superdotação, v. 1, n. 1, jan./jun. 2013. p.21-30. Disponível em:

<https://conbrasd.org/docs/2_PUBLICACAO/REVISTAS/REVISTA_N_1.PDF\#page=21>. Acesso em: 09 de jun. 2020.

RANGNI, Rosemeire de Araújo; COSTA, Maria da Piedade Resende da. A educação dos superdotados: história e exclusão. Revista Educação-UNG-Ser, v. 6, n. 2, p. 16-24, 2011. Disponível em: <http://revistas.ung.br/index.php/educacao/article/view/923>. Acesso em: 07 de maio 2020.

ROMMELSE, Nanda et al. An evidenced-based perspective on the validity of attentiondeficit/hyperactivity disorder in the context of high intelligence. Neuroscience \& Biobehavioral Reviews, v. 71, p. 21-47, 2016. Disponível em: <http://dx.doi.org/10.1016/j.neubiorev.2016.08.032>. Acesso em: 28 de ago. 2020. 
SCHWARTZMAN, J. S. Transtorno de Déficit de Atenção. São Paulo: Memmon. 2001.

UEHARA, Emmy; CHARCHAT-FICHMAN, Helenice; LANDEIRA-FERNANDEZ, Jesus. Funções executivas: um retrato integrativo dos principais modelos e teorias desse conceito. Neuropsicologia Latinoamericana, Calle, v. 5, n. 3, p. 25-37, 2013 . Disponível em $<$ http://pepsic.bvsalud.org/scielo.php?script=sci_arttext\&pid=S2075-

94792013000300004\&lng=pt\&nrm=iso >. Acesso em: 25 out. 2020.

VIRGOLIM, Angela Mágda Rodrigues. A contribuição dos instrumentos de investigação de Joseph Renzulli para a identificação de estudantes com Altas Habilidades/

Superdotação. Revista Educação Especial, v. 27, n. 50, p. 581-610, 2014. Disponível em: <https://periodicos.ufsm.br/educacaoespecial/article/view/14281/pdf>. Acesso em: 24 de abr. 2020. 